


\section{pco training:}

\section{Six areas of competence required by the GDC}

- Health and safety

- Infection control

- CPR, medical emergencies, and common dental emergencies

- Personal Development Plans, reflective learning, and CPD skills

- Working with dentists and patients

- Ionising radiation

Panel 1

particularly helpful in situations where a dental nurse is not able to get access to a computer. The tutor version has PowerPoint presentations with links to the e-learning programme, student handouts, assessment questions and certificates. The tutor version is not reproducible, and is only available to accredited training organisations such as deaneries, dental schools and City and Guilds and National Examining Board for Dental Nurses training centres.

Like ART, DNART does not give a qualification but is designed to be a stepping stone to the NVQ in Oral Healthcare (Dental Nursing) at level three and actually gives the knowledge and understanding needed for six of the current nine mandatory units in that qualification. It is also an excellent learning resource for all members of the dental team wishing to update their current knowledge. The programme for dental nurses to use will be sent to every NHS dental practice free of charge in England and Wales in early September. Should accredited tutors want the special tutor version they will be able to apply to the KSS Deanery who will send the first copy for free but charge a small fee for further copies.

\section{Future perfect}

When dental nurses have registered can they sit back and relax? Probably not; all PCDs including dental nurses will be responsible to the GDC for practising within the limits of their competence. Dentists will of course remain the team leaders and will be responsible to the GDC for making sure they do not ask team members to perform tasks that are beyond their training and skills. Clear guidelines will be issued to dentists and all classes of PCDs on their roles and responsibilities.

Although the GDC will not commit to when and how much, mandatory continuing professional development (CPD) will follow for all classes of PCDs. But this will mean more training and education and the costs associated with it. With a registered qualification will come responsibility and a new level of professionalism. Just as dentists are subject to compulsory CPD to stay on the register all classes of PCDs will need to embrace 'lifelong learning' and keep their skills and knowledge up to date.

Case Study: ART helps nurse build career

A

dental nurse who has benefited from ART is Emma Maskell from Sussex. She works in a busy single-handed dental practice in Hove. When she began ART in March 2005 she had worked as a dental nurse for only a few months. She has a background in science, has been studying a foundation course, and worked for the past two years. Twenty two year old Emma's previous job was as a postal worker.

She decided on a career in dentistry because she was looking for a healthcare role in which she could hopefully advance and increase her knowledge base.

After a few weeks as a dental nurse she decided that she had made a good move and would like to begin some training. Information on which course to do and how to fund it was a challenge.

There was often conflicting advice on the best plan of action that would not compromise her duties, patients and colleagues but still fulfil her training requirements. However her dentist Mr Garland was keen for her to study and willing to support her financially.

The practice had recently received information about ART courses in their area from the Kent, Surrey and Sussex Deanery.

Emma decided to go to Chichester hospital to do the six module ART programme. Along with nine other student nurses with varying levels of experience but no formal qualification, this was Emma's introduction to the theory behind the daily work in her surgery.

Emma said she found the study days were pitched at a level for her to understand even though she was fairly new to dentistry. She was impressed with the tutors' knowledge on the latest legislation and advice. As her teachers were all working dental nurses they were also able to discuss contemporary real life situations with the students.

After the ART course, Emma said she felt more confident in the practice and more informed on health and safety issues. She was able to see how vital it was for a dental nurse to have a good understanding of both the theory and practice of dentistry.
There were one or two modules that Emma was not able to complete due to a booked holiday. However with the introduction of DNART she will be able to complete the course using the CD-ROM and have her certificates of competence ready for the GDC.

What next for her? Well with ART under her belt Emma has decided to undertake the NVQ in Oral Healthcare (Dental Nursing) at level three at Brighton College in September. She will attend the course for three hours one evening per week. Her work colleagues, including a dentist, hygienist, and dental nurse, have expressed their support and are keen to help her with any project work. An NVQ Assessor will attend the practice at regular intervals to observe Emma at work. The knowledge and understanding Emma received by completing ART will count for six of the currently mandatory nine units in the NVQ qualification.

For further information on any of the issues in this article please email Karen Silverthorne at kathrynm@ btconnect.com 